\title{
A new method for measuring fuel flow in an individual injection in real time
}

\author{
Felix Leach, Martin Davy, Manus Henry, Michael Tombs, Feibiao Zhou \\ University of Oxford
}

Copyright $\odot 2018$ SAE International

\begin{abstract}
Knowledge of fuel mass injected in an individual cycle is important for engine performance and modeling. At the moment, such measurements are not possible on-engine or in real-time. In this paper, a new method using Coriolis flow meters (CFMs) and a new, patented, signal processing technique, known as the Prism, is introduced. CFMs are extensively used for flow measurement both in the automotive industry and further afield, and when coupled with the Prism have the potential to make these challenging high-speed measurements. A rig-based feasibility study was conducted injecting very small quantities of diesel $(3 \mathrm{mg})$ at pressures of up to $1000 \mathrm{bar}$ at simulated engine speeds of up to $4000 \mathrm{rpm}$. The results show that these small quantities can in principle be measured. The results also reveal a previously unknown behaviour of CFMs when measuring very low flow rates at high speed. The study concludes that by combining high-resonant frequency flow tubes with the Prism technology in a new instrument - the Fast Next Generation Coriolis (Fast-NGC) flow meter-it will be possible to measure individual injector flow rates on-engine in real-time.
\end{abstract}

\section{Introduction}

Information about the mass of fuel injected into the combustion chamber during a fuel injection event is essential for combustion control, and hence fuel consumption and emissions control. For example, the mass of fuel injected can be reduced due to deposit formation on fuel injectors $[1,2]$. These deposits have also been shown to lead to an increase in unburned hydrocarbon (UHC) emissions [3]. Such deposit formation is unlikely to occur evenly on all fuel injectors fitted in an engine and such cylinder-to-cylinder variations in emissions or fuel consumption cannot be identified using standard techniques, which average results over all cylinders.

Detailed information on rate of fuel injection into the cylinder is essential for combustion modelling in CFD packages [4], with minor changes in the rate of injection leading to significant differences in modelled heat release. With digital rate shaping injection technology becoming more commonplace as a combustion control tool, detailed knowledge of the rate of fuel injection is increasingly important as the injected quantity of closely spaced injections will be affected by the rail pressure dynamics $[5,6]$. If such information were available in real-time then it could give direct feedback to the fuel injection controller.

Existing measurement of flow in injectors is achieved by a variety of means $[5,7]$ but the most commonly used technique is the Bosch method, where fuel is injected into a filled tube, and an analysis of

Page 1 of 9 the pressure waves is used to obtain the flow rate information [8]. As such, fuel flow measurement of individual injections has been developed for an offline, test bench application.

Coriolis mass flow meters are widely used for industrial mass flow measurement across a broad range of industry sectors. Many automotive research facilities employ Coriolis flow meters (CFMs) as part of their fuel flow measurement system $[9,10]$. Usually CFMs are positioned far from the engine and someway downstream of the fuel injection system, as they can be very sensitive to external vibration. Coriolis meters have two parts - a flow tube and a transmitter. Figure 1 shows a simplified "wire-frame" model of a fluid particle of mass $d m$ passing through a flow tube at velocity $v$. The flow tube is a pipework that is oscillated (about the A-D axis in Figure $1, \varnothing$ ) by the transmitter at one of the modes of the natural frequency of mechanical vibration (typically $50 \mathrm{~Hz}-1 \mathrm{kHz}$ ) which is dependent on the mass and geometry of the flow tube. Two sensors (roughly in the positions of F1, and F2 in Figure 1) monitor the flow tube velocity and hence its vibration [11]. Given that the flow tube has both a fixed mass and a fixed volume, the total mass of the flow tube-fluid system is solely dependent on the density of the fluid therefore measurement of the frequency of vibration enables the fluid density to be calculated. Arising from the flow tube geometry, the coriolis acceleration $(2 v \dot{\varnothing})$ of the fluid generates a phase difference between the two sensors (at F1 and F2) which is proportional to the mass flow from simple Newtonian analysis. Because of the nature of the mechanism of flow measurement (and the fact that they measure mass flow directly) CFMs are in theory well suited to measuring transient fuel events such as during fuel injection. 


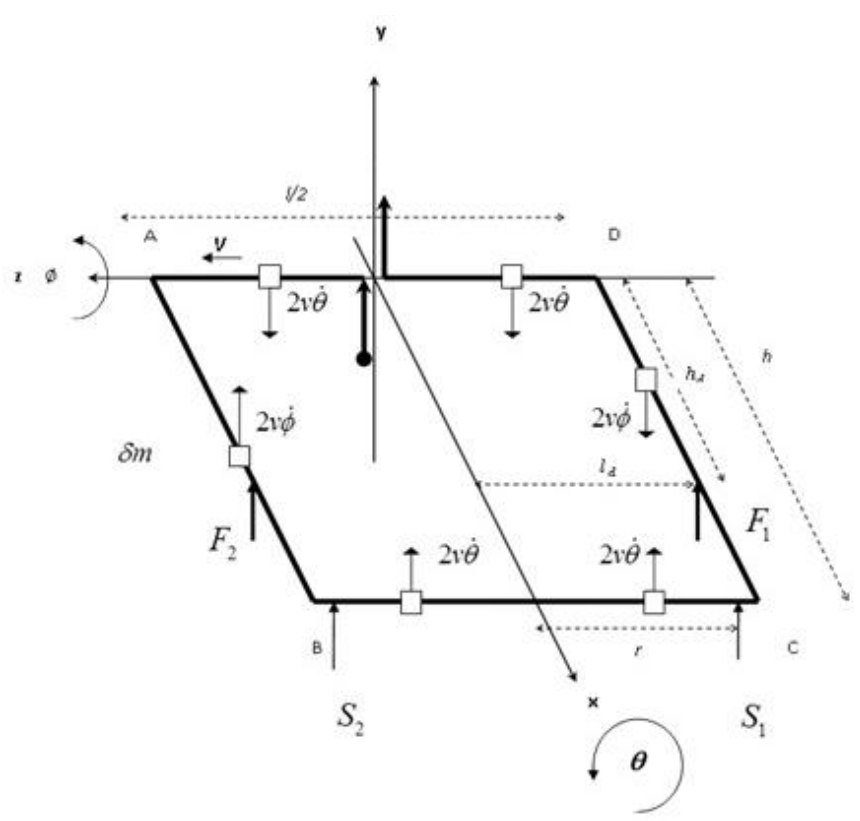

Figure 1: Simplified "wire-frame" model of a flow tube as a mass $d m$ (square box) travels around the flow tube

The aim of this work is to exploit the characteristics of CFMs, alongside the new Prism techniques, to measure fuel injection in an individual diesel injection and, assuming this is possible, to understand the effect of placing a CFM immediately upstream of the inlet of a fuel injector.

\section{Experimental methodology}

\section{Test rig}

The tests reported in this work were undertaken on a static diesel injection rig. A schematic of this rig is shown in Figure 2, the injector in Figure 3, and a photo of the rig in Figure 4. The rig injects diesel fuel at pressures of up to 1000 bar into a cylindrical glass spray chamber, which is at ambient pressure. The fuel is pressurised using a Maximator M189LVE pump; two CFMs measure fuel flow on the feed to the injector (at pressures of up to 1000 bar) and on the spill/return from the injector (at pressures of around to $0.5 \mathrm{barG}$ ). The spray into the chamber is imaged by a high speed camera with back illumination from an LED array. The pressures either side of the high pressure CFM are recorded by high speed pressure transducers, while the pressure in the return is monitored by a low speed pressure transducer.

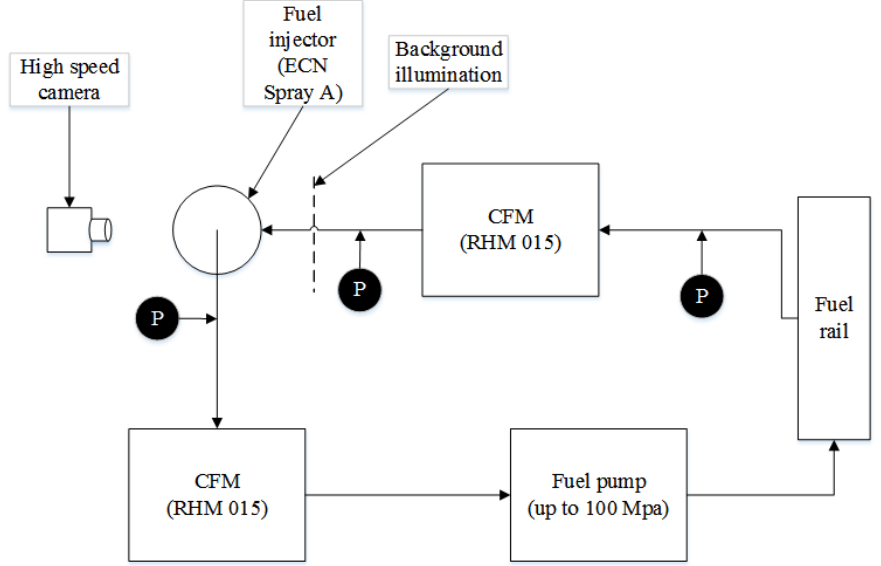

Figure 2: Schematic of the test rig - "P" indicates the location of pressure measurement

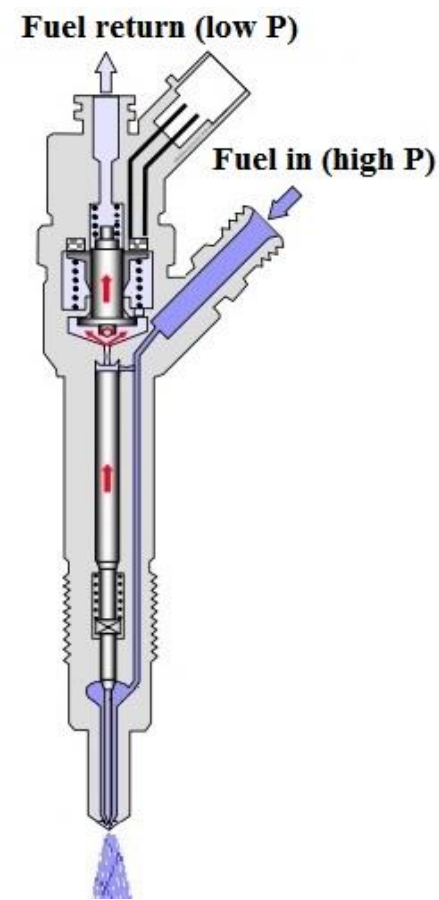

Figure 3: Schematic of a single hole solenoid diesel injector showing fuel inlet and return flows during injector operation. Adapted from [12]. 


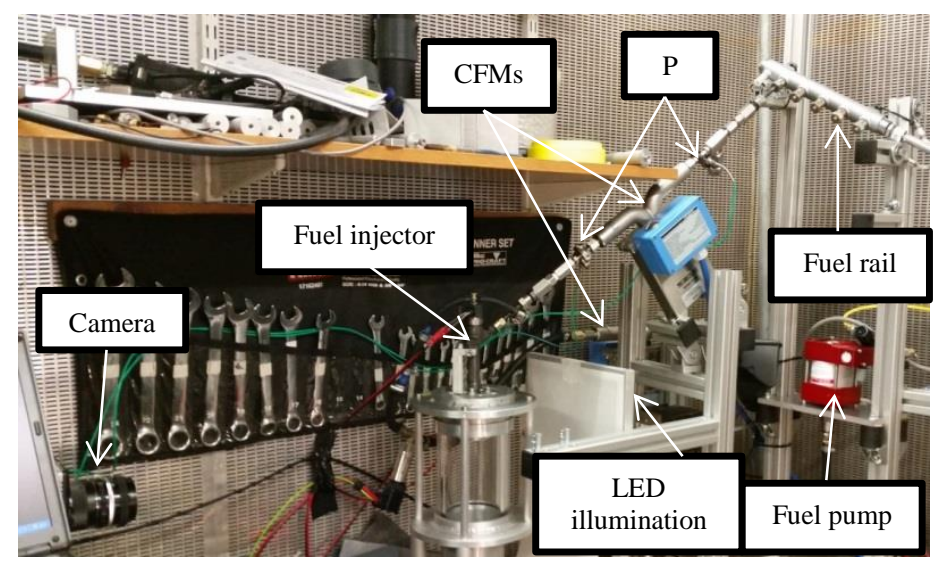

Figure 4: Photo of the test rig - "P" indicates the location of pressure measurement

\section{Fuel injector}

In order to trial this technique against a well characterised injector, the ECN Spray A single hole solenoid diesel injector [13] was used as a test injector for this work. Payri et al. have developed a very useful online rate shape calculator $[14,15]$ for this injector, against which this data is compared. The experimental test rig has been designed to be as close as possible to the ECN specifications, and is identical other than differences associated with mounting two CFMs. The injector was actuated using a National Instruments Direct Injector Driver System (DIDS) capable of controlling the current profile driving the injector for a given Energising Time (ET). More information on the operating principles of solenoid diesel injectors can be found in $[12,16]$.

\section{CFM flow tubes}

As stated in the introduction, the flow tubes are the vibrating mechanical component of a Coriolis Flow Meter (CFM). The flow tubes used in this work are RHM 015 tubes, supplied by Rheonik $\mathrm{GmbH}$ available off-the-shelf. They are a twin parallel loop design, operating at a maximum pressure of up to 1050 bar and have a driven vibration frequency of approximately $150 \mathrm{~Hz}$. The high pressure rating of this flow tube model was developed for Hydrogen filling station applications.

The flow tubes have an overall length (face-to-face) of $220 \mathrm{~mm}$, which when combined with the other pipework needed to plumb in the flow tubes gives an overall rail to injector inlet length of $72 \mathrm{~cm}-$ substantially larger than the $24 \mathrm{~cm}$ that the Spray A guidance [17] specifies, however given the limitations of the flow tubes this was unavoidable. Future development work will include reducing this distance.

\section{Instrumentation}

Fuel pressure has been measured both upstream and downstream of the Coriolis fuel meter with two Kistler 4067 high speed pressure transducers approximately $35 \mathrm{~mm}$ upstream and downstream of the flow meter. These transducers, alongside other pressure data, and the injection current signal were logged by a National Instruments data acquisition system at up to $125 \mathrm{kHz}$.
A Photron FASTCAM-1024PCI model 100K colour camera was used to record the fuel injection at a rate of 5000 frames per second (fps), at a resolution of up to $128 \times 816$ pixels which best captured the spray. The fuel spray was back illuminated using an LED array, pulsed synchronously with the spray. The spray images were analysed using an in-house code which captures the plume from an image which is fully described in [18-20].

The CFMs are controlled and data from them logged using a pair of prototype transmitters. The transmitter design is based on a Zynq7000 chip, incorporating two ARM Cortex-A9 processors. Flow data is logged at $48 \mathrm{kHz}$ to provide effective signal reconstruction using the Prism technique (see signal processing section). This system is capable of providing mass flow measurements in real-time, and there is enough memory on board, in the current design iteration, to log around $50 \mathrm{~s}$ of data.

\section{Test conditions}

The test conditions were set in accordance with the preferred Spray A parametric variations [21] subject to an upper limit on fuel pressure of 1000 bar set by the flow tubes. The experimental test conditions are shown in Table 1, and the current profiles used to drive the injector at the three different ETs are shown in Figure 5.

Table 1: Experimental test conditions

\begin{tabular}{|l|l|l|l|}
\hline Test point & 1 & 2 & 3 \\
\hline Fuel Pressure (bar) & 1000 & 1000 & 1000 \\
\hline ET (ms) & 0.795 & 2.5 & 0.1 \\
\hline $\begin{array}{l}\text { Injection duration } \\
(\mathrm{ms})\end{array}$ & $\sim 1.5$ & $\sim 4$ & 0 \\
\hline Total injected mass* & 3.35 & 9.11 & 0 \\
\hline
\end{tabular}

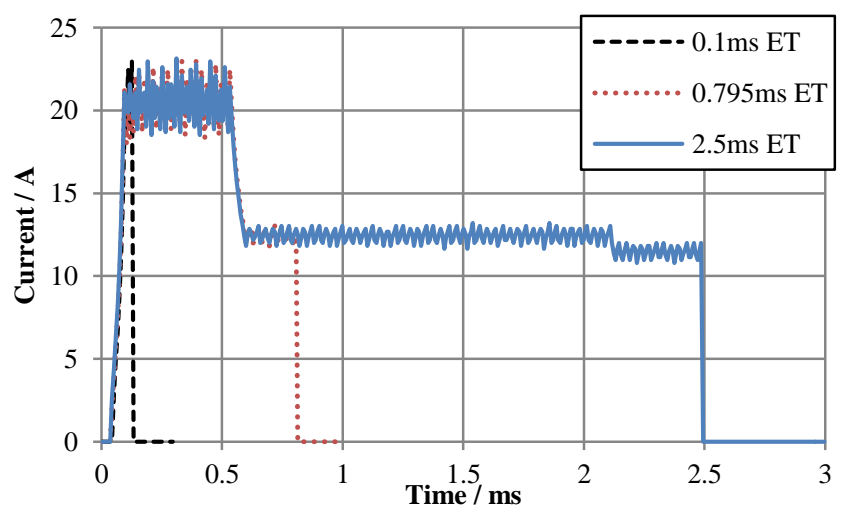

Figure 5: Injector drive current profiles for the three ETs tested

These tests were undertaken at a variety of injection frequencies representing four-stroke engine speeds of 1000, 2000, 3000, and $4000 \mathrm{rpm}$. A further test used an injection frequency that was a multiple of the flow tube drive frequency $(148 \mathrm{~Hz})$, which corresponds to a four-stroke engine speed of $1800 \mathrm{rpm}$. 
The test fuel was a diesel fuel compliant with EN590 [22], the specifications of which are shown in Table 2:

Table 2: Diesel fuel composition

\begin{tabular}{|l|l|}
\hline Density $(\mathrm{kg} / \mathrm{L})$ & 0.8327 \\
\hline Cetane Number & 53.0 \\
\hline IBP $\left({ }^{\circ} \mathrm{C}\right)$ & 171.4 \\
\hline FBP $\left({ }^{\circ} \mathrm{C}\right)$ & 355.0 \\
\hline Aromatics $(\% \mathrm{~m} / \mathrm{m})$ & 25.1 \\
\hline Sulfur $(\mathrm{mg} / \mathrm{kg})$ & 6.5 \\
\hline FAME $(\% \mathrm{v} / \mathrm{v})$ & $<0.1$ \\
\hline
\end{tabular}

\section{CFM signal processing}

The Coriolis meter outputs were processed in real time using a new signal processing technique, developed at Oxford University, known as the Prism. Prism signal processing uses recursive Finite Impulse Response (FIR) filtering to carry out a variety of tasks, such as notch filtering of undesired frequency components and the tracking of sinusoidal signals. For the Coriolis application, the CFM sensor signals, which are essentially sinusoidal in nature, are processed using a chain of Prisms to notch out undesired mechanical vibrations and then to track the frequency, amplitude and phase of each sensor signal, and hence the phase difference. More information on the prism filtering can be found in [23-25] and a discussion on its application to this technique is included in [26]. This Prism filtering runs in real-time and does not need post-processing to obtain the flow rate information.

\section{Results}

Figure 6 shows experimental data from test point 2 processed using Prism signal processing in two different ways: in the first ('raw data') Prisms are used to track frequency, phase and amplitude of the sensor signals without pre-filtering. In the second ('notch filtered data') additional Prisms are used to notch out undesired modes of vibration in a pre-filtering stage; the effectiveness of the Prism notch filters is clearly seen. The CFM is measuring a series of injections at test point 2 at a simulated engine speed of $3000 \mathrm{rpm}$. No useful information is available from the raw signal, but with notch filtering applied, consecutive injection pulses can clearly be seen. However despite the fuel injections being of the same mass, the measured signal differs in amplitude significantly and is not particularly repeatable. The reasons for this are discussed in a later section.

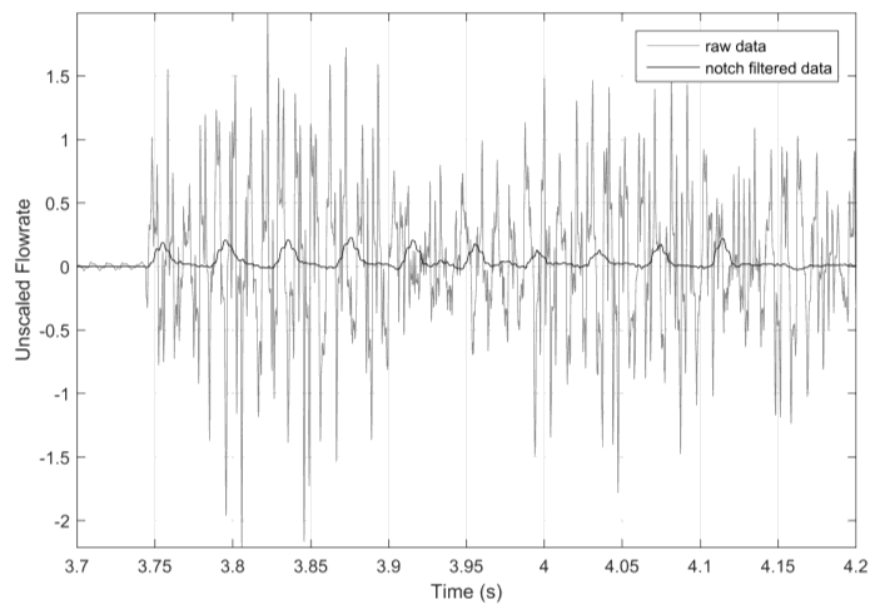

Figure 6: Comparison of raw data and notch filtered data at test point 2, and an equivalent engine speed of $3000 \mathrm{rpm}$, showing clearly the effect of the prism signal processing

The measured mass flow from a single shot injection at test point 1 is shown in Figure 7. It can be seen that there is a clear single mass flow pulse measured by the CFM. It is also reassuring that this pulse returns to zero immediately after the single shot injection. However, given that the true pulse duration is $1.5 \mathrm{~ms}$, the mass flow measured by the CFM is non-zero over a significantly longer period. The true (short) pulse length is confirmed by the high-speed pressure information shown in Figure 8. The pressure data shows that the pressure (and by implication the flow) has returned to its initial value around $4 \mathrm{~ms}$ after SOI. Figure 8 also shows that the CFM is acting as a plenum, in effect a surrogate fuel rail, as the pressure downstream of the CFM shows a significant drop on injection, whereas the pressure upstream is barely affected. The pressure wave caused at the end of injection is also clearly seen to be propagating through the system.

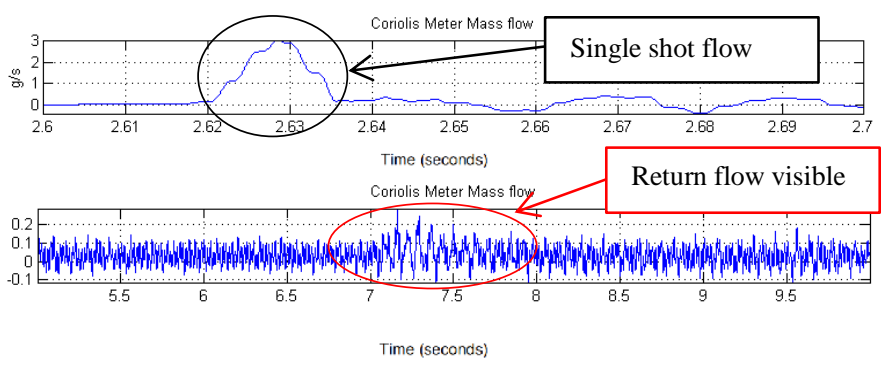

Figure 7: Coriolis feed (upper) and return (lower) line data from a single shot injection at 1000 bar of duration $1.5 \mathrm{~ms}$ (test point 1). (Note here that the two meters were taken with different time-bases so the relative time axes are correct, but not the absolute) 


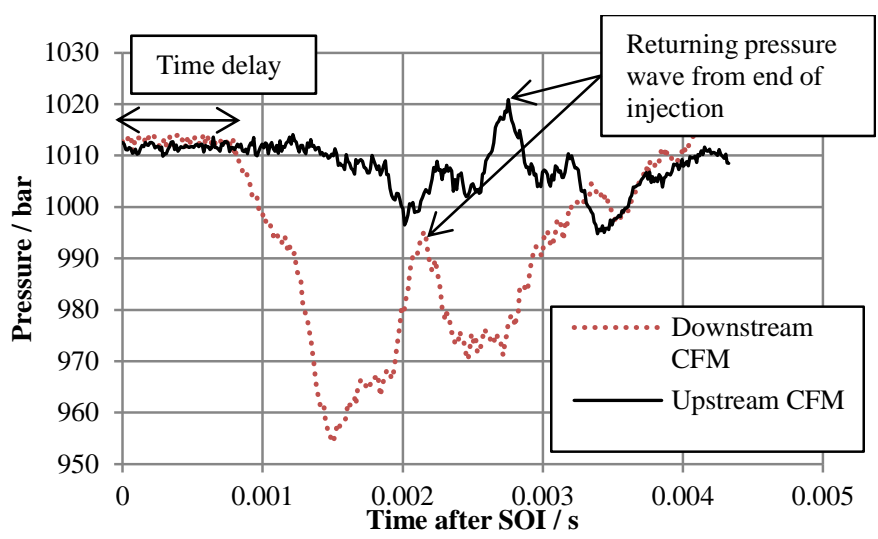

Figure 8: Pressure upstream and downstream of the CFM from a single shot injection test point 1

As an alternative means of estimating how much fuel has been injected, the fuel spray has been imaged. A series of shadowgraphtype images from test point 1 are shown in Figure 9. These show the injected fuel plume penetrating into the spray chamber, and reveal that a small amount of the plume is outside the field of view of the camera. Nevertheless by integrating the plume, a guide to the amount of fuel injected can be obtained, and this compared with the value from the CFM. The integrations of the spray plume at test points 1 and 2 are shown in Figure 10. Reassuringly the first $1.5 \mathrm{~ms}$ of data from both test points are identical, giving validation to the technique, and the amount of fuel injected in the $4 \mathrm{~ms}$ injection (test point 2) continues to increase.

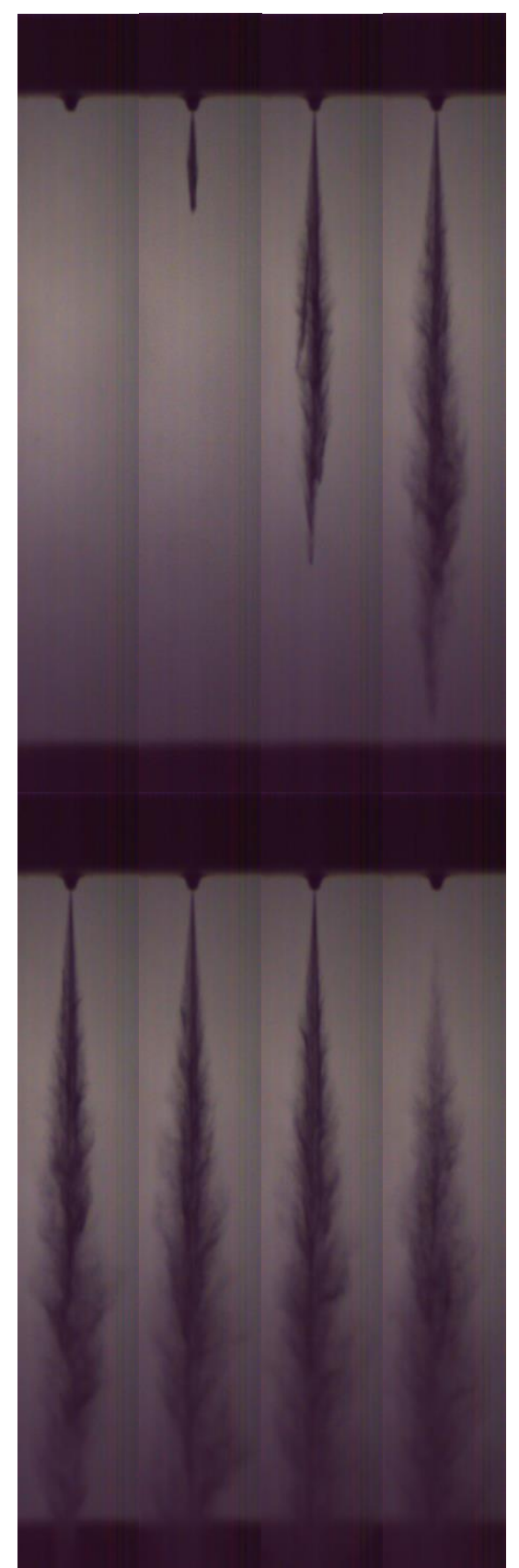

Figure 9: Spray images from test point 1, the integral of these images is shown as the blue line on Figure 10. Each image is taken $0.2 \mathrm{~ms}$ apart 


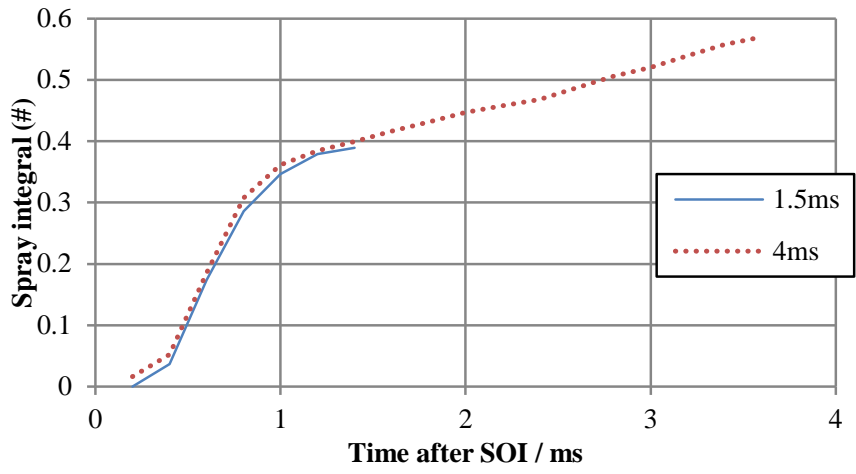

Figure 10: Plume integrals for test points $1 \& 2$. These give a guide as to the amount of fuel injected

Figure 11 shows the CFM measured flow data at test point 2. As for test point 1 , distinct individual injections are clearly seen, however the duration of each is longer than expected, and the peak amplitude varies, despite the sequence being nominally constant $4 \mathrm{~ms}$ injections of $9.11 \mathrm{mg}$. Figure 12 shows the pressure data from this test point, and indicates that the pressure drop is substantially larger than that at test point 1, consistent with a higher fuel flow. Again, the effect of the injections on the upstream flow meter is negligible, showing that the CFM is acting as a plenum.

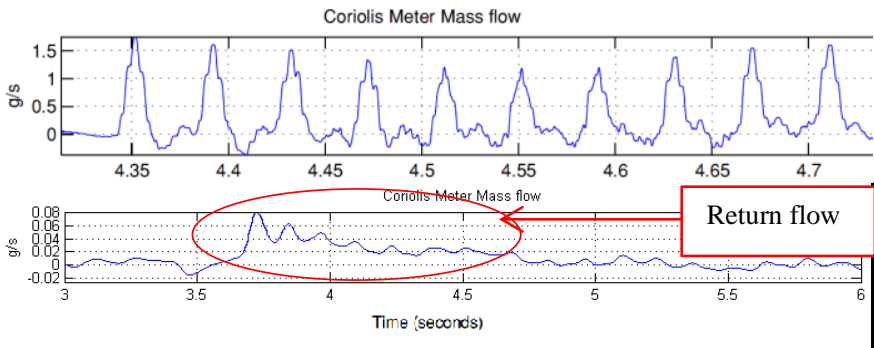

Figure 11: Coriolis feed (upper) and return (lower) line mass flow from a series of injections at 1000 bar of duration $4 \mathrm{~ms}$ at a simulated engine speed of $3000 \mathrm{rpm}$ (test point 2). (Note here that the two meters were taken with different time-bases so the relative time axes are correct, but not the absolute)

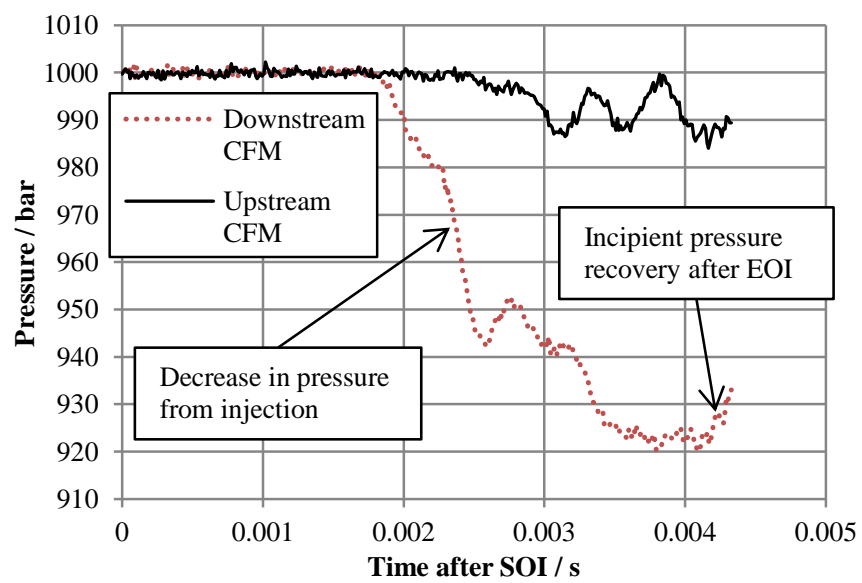

Figure 12: Pressure upstream and downstream of the CFM from a single shot injection test point 2

\section{Very short ET - no fuel injected}

Figure 13 shows the signal from the feed and return CFMs for a single injection with an ET of $0.1 \mathrm{~ms}$. Inevitably with such a small ET, the signal is noisy as the fuel quantities involved are so low. Such short ETs are not commonly used at the moment, however as DRS technology increases in use, such small ETs are expected to become more relevant. At this condition flow can clearly be seen on both meters, and this is confirmed by looking at the fuel pressure data (Figure 14), showing a decrease in pressure consistent with fuel flow into the injector. However, looking at the images from the highspeed camera of this injection (Figure 15), no fuel can be seen to be injected. This suggests that what is happening with this very short ET is that some flow is beginning to enter the injector as the needle is energised, however the needle closes (or never fully opens) before any flow can leave the injector tip - this flow is instead being sent to the spill line rather than injected into the spray chamber.

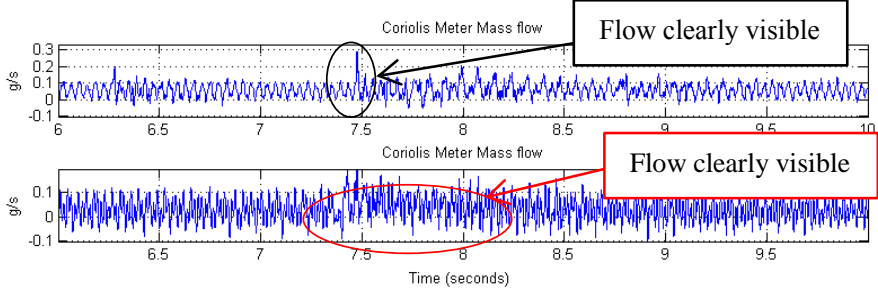

Figure 13: Coriolis feed (upper) and return (lower) line data for the 1000 bar, $0.1 \mathrm{~ms}$ ET case. Flow can clearly be seen in both lines

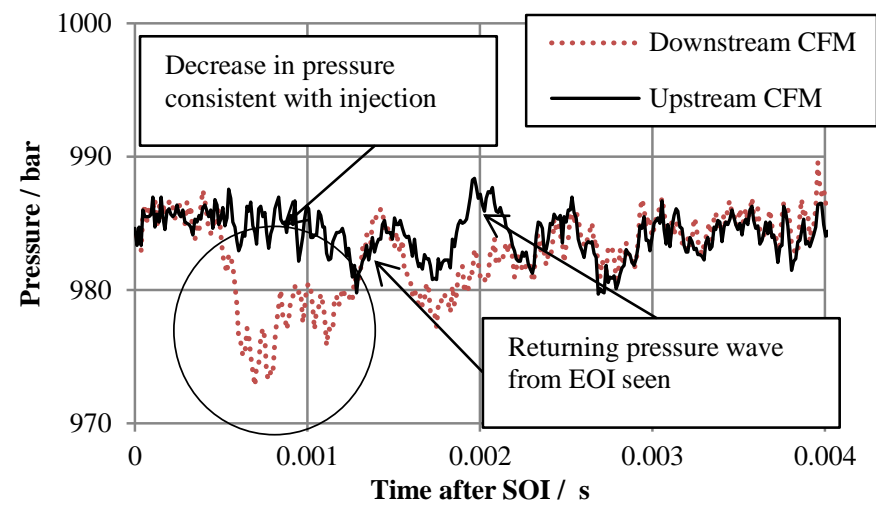

Figure 14: Fuel pressure either side of the CFM for the 1000 bar, $0.1 \mathrm{~ms}$ ET case. A drop in pressure downstream of the CFM can be seen, consistent with fuel flow 


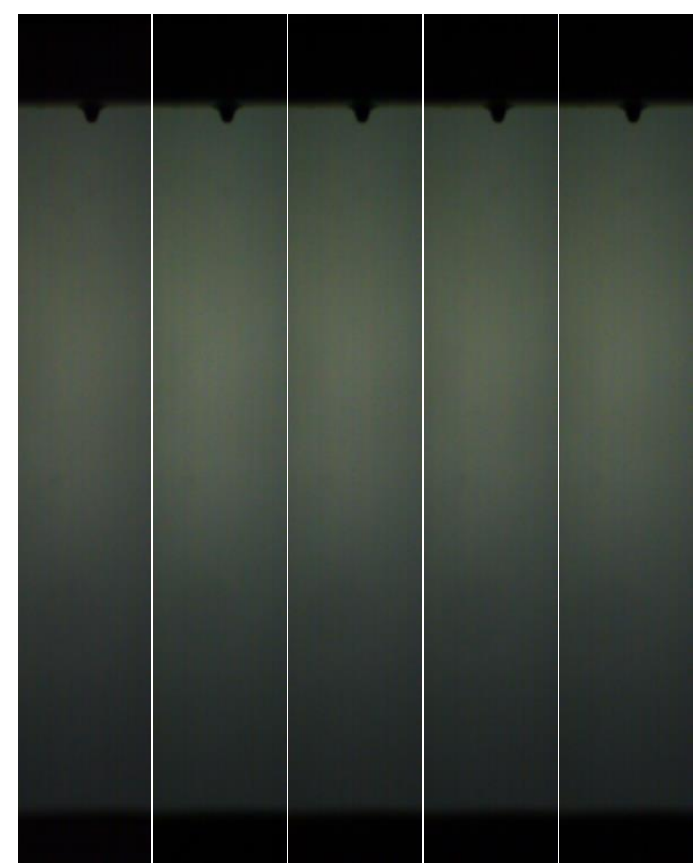

Figure 15: "Spray" images for test point 3 (1000 bar, $0.1 \mathrm{~ms}$ ET). No injected fuel can be seen in the images despite flow on the Coriolis meters. Each image is taken $0.2 \mathrm{~ms}$ apart

\section{Impact of flow meter phase and vibration frequency}

It is hypothesised that the lack of repeatability in the results shown in Figure 6 and Figure 11, might be due to the fact that the injection durations are substantially shorter than the period of the CFM drive oscillations $(6.76 \mathrm{~ms})$. Additional experimental work suggested that the CFM observed peak flow rate might be a function of the position (or phase) of the flowtube oscillation at the start of the injection.

A new experiment was devised to test this hypothesis. A series of $1.5 \mathrm{~ms}$ injections were undertaken at a frequency that is a direct multiple of the CFM drive frequency $(14.8 \mathrm{~Hz})$, so that the injection will be taking place at approximately the same phase in the Coriolis drive cycle. The results from this test are shown in Figure 16. It can clearly be seen that the peak amplitudes of the injected mass flow are now (almost) constant. The small variation in peak amplitude is, we suggest, caused by a small difference between the injection frequency and exactly ten times the resonant frequency.

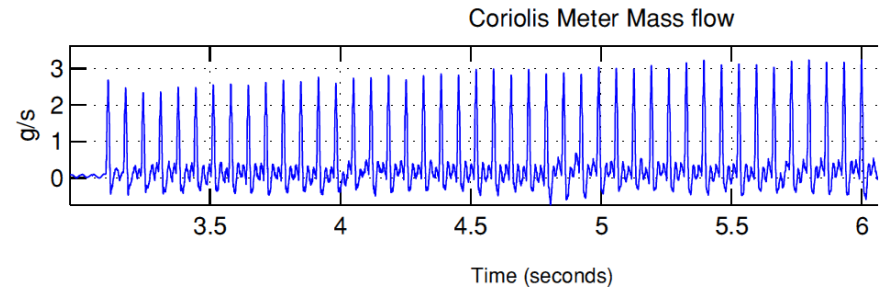

Figure 16: Mass flow rate measured from a series of identical injections at $14.8 \mathrm{~Hz}$. The coriolis dive frequency is $148 \mathrm{~Hz}$. Excellent repeatability is observed

Page 7 of 9
Another effect of the relatively low flowtube vibration frequency is that it appears to elongate the observed injection duration. Both Figure 7 and Figure 11 show this clearly; where (respectively) there should be injection durations of $1.5 \mathrm{~ms}$ and $4 \mathrm{~ms}$, the measured durations are in both cases around 15-20 ms. Again this is likely caused by the "slow" oscillation frequency of the meter acting as a mechanical filter on the system, extending the measured injection durations, despite the pressure data indicating that this is not what is physically happening.

\section{Discussion}

This paper reports the outcome of a short (three month) feasibility study into whether this technique is viable for further development, and these results are inevitably preliminary. Significantly, the Prism signal processing has been shown to be valuable in enabling a CFM to measure fuel flow at the entrance to a diesel injector at high pressure (up to 1000 bar). Prism runs in real time (in this application at $48 \mathrm{kHz}$ ) and requires no post-processing to obtain mass flow rates. However, addition Prism-based notch filtering is required to remove unwanted mechanical vibrations in order to discern useful flow information from the CFM signals (Figure 6).

One clear outcome from this work is the effect of the flowtube resonant frequency, which impacts both the observed peak flow and injection duration. All of the injection durations tested were shorter than the oscillation period of the flow tube, and it is suggested that the observed mass flow is a function of the flowtube oscillation phase at the time of injection (Figure 16). In addition this long oscillation period increases the signal's measured duration in the time domain. An effect of using off-the-shelf flow tubes (as in this work) is that they act as a plenum, with the pressure upstream of the flow tube being almost unaffected by the fuel injection, even at the longest injection duration tested.

The use of the ECN Spray A injector means that very small quantities of fuel were injected - far smaller than would be injected in a typical engine cycle. Despite these very small quantities, all were clearly observed using the CFMs with the Prism signal processing. Test points when the ET of the injector is so small that no fuel is actually injected (Figure 13 and Figure 15), perhaps indicative of future DRS trends, showed that flow is still measured passing from the feed to the spill. The CFMs with the Prism signal processing clearly observed this too, showing the power of this technology for future engine control strategies.

\section{Summary/Conclusions}

This work has applied a new signal processing technique known as Prism to signals from a Coriolis Flow Meter (CFM) when applied to short duration fuel injections at pressures up to 1000 bar. The results show that:

1. The Prism signal processing technique is a hugely powerful tool when used on this application. Previously unresolvable signals can now clearly show mass flow rate from fuel injections at simulated engine speeds of up to $4000 \mathrm{rpm}$.

2. The relatively low resonant frequency of the flow tubes acts as a mechanical filter on the system, elongating the observed injection durations, among other undesirable effects. Future flow tubes for this application will need to have significantly higher resonant frequencies. 
3. Even when the ET of a diesel injector is reduced to shorter than the duration at which fuel is injected, the CFM with Prism signal processing are able to observe fuel passing from the injector feed to the spill without any fuel injected into the cylinder.

This work has developed a toolbox of techniques to evaluate this new measurement approach and take it forwards. The results at this early stage are very promising and show the potential for CFMs, combined with Prism signal processing, to be used to measure injected fuel mass on a cycle resolved basis, on-engine, in real-time.

\section{References}

1. Aradi, A., Imoehl, B., Avery, N., Wells, P. et al., The Effect of Fuel Composition and Engine Operating Parameters on Injector Deposits in a High-Pressure Direct Injection Gasoline (DIG) Research Engine, SAE Technical Paper 1999-01-3690, 1999, https://doi.org/10.4271/1999-01$\underline{3690 .}$.

2. $\quad$ Birgel, A., Ladommatos, N., Aleiferis, P., Zülch, S. et al., Deposit Formation in the Holes of Diesel Injector Nozzles: A Critical Review, SAE Technical Paper 2008-01-2383, 2008, https://doi.org/10.4271/2008-01-2383.

3. Pos, R., Avulapati, M., Wardle, R., Cracknell, R. et al., Combustion of ligaments and droplets expelled after the end of injection in a multi-hole diesel injector. Fuel, 2017. 197: p. 459-466. https://doi.org/10.1016/j.fuel.2017.02.048.

4. Leach, F., Ismail, R., Davy, M., Weall, A. et al., Comparing the Effect of Fuel/Air Interactions in a Modern High-Speed Light-Duty Diesel Engine, SAE Technical Paper 2017-24-0075, 2017. https://doi.org/10.4271/201724-0075.

5. Ferrari, A. and A. Mittica, Response of different injector typologies to dwell time variations and a hydraulic analysis of closely-coupled and continuous rate shaping injection schedules. Applied Energy, 2016. 169: p. 899-911, https://doi.org/10.1016/j.apenergy.2016.01.120.

6. Jörg, C., Schnorbus, T., Jarvis, S., Neaves, B. et al., Feedforward Control Approach for Digital Combustion Rate Shaping Realizing Predefined Combustion Processes, SAE Int. J. Engines 8(3):1041-1054, 2015, https://doi.org/10.4271/2015-01-0876.

7. Arcoumanis, C. and Baniasad, M., Analysis of Consecutive Fuel Injection Rate Signals Obtained by the Zeuch and Bosch Methods, SAE Technical Paper 930921, 1993, https://doi.org/10.4271/930921.

8. Marčič, M., Measuring method for diesel multihole injection nozzles. Sensors and Actuators A: Physical, 2003. 107(2): p. 152-158, https://doi.org/10.1016/S09244247(03)00205-X.

9. Turner, J., Popplewell, A., Patel, R., Johnson, T. et al., Ultra Boost for Economy: Extending the Limits of Extreme Engine Downsizing, SAE Int. J. Engines 7(1):387-417, 2014, https://doi.org/10.4271/2014-01-1185.

10. Alriksson, M., Rente, T., and Denbratt, I., Low Soot, Low NOx in a Heavy Duty Diesel Engine Using High Levels of EGR, SAE Technical Paper 2005-01-3836, 2005, https://doi.org/10.4271/2005-01-3836.

11. Henry, M.P., Clarke, D.W., Archer, N., Bowles J., et al., A self-validating digital Coriolis mass-flow meter: an overview. Control Engineering Practice, 2000. 8(5): p. $487-$ 506, https://doi.org/10.1016/S0967-0661(99)00177-X.
12. Bosch, Diesel-Engine Management. 5th ed. 2005: Robert Bosch GmbH.

13. Bardi, M., Payri, R., Malbec, L.M., Bruneaux, G., et al., Engine Combustion Network: Comparison of Spray Development, Vaporization, and Combustion in Different Combustion Vessels. Atomization and Sprays, 2012. 22(10): p. 807-842, https://doi.org/10.1615/AtomizSpr.2013005837.

14. Payri, R., Salvador, F.J., Gimeno, J., Bracho, G., et al., A New Methodology for Correcting the Signal Cumulative Phenomenon on Injection Rate Measurememts. Experimental Techniques, 2008. 32(1): p. 46-49, https://doi.org/10.1111/j.1747-1567.2007.00188.x.

15. Pickett, L., Manin, J., Payri, R., Bardi, M. et al., Transient Rate of Injection Effects on Spray Development, SAE Technical Paper 2013-24-0001, 2013, https://doi.org/10.4271/2013-24-0001.

16. Bosch, Automotive Handbook. 8th ed. 2011: Robert Bosch $\mathrm{GmbH}$

17. Dahlstrom, J., Andersson, O., Tuner, M., and Persson, H., Experimental Comparison of Heat Losses in Stepped-Bowl and Re-Entrant Combustion Chambers in a Light Duty Diesel Engine, SAE Technical Paper 2016-01-0732, 2016, https://doi.org/10.4271/2016-01-0732.

18. Leach, F., Stone, R., and Richardson, D., The Influence of Fuel Properties on Particulate Number Emissions from a Direct Injection Spark Ignition Engine, SAE Technical Paper 2013-01-1558, 2013, https://doi.org/10.4271/201301-1558.

19. Leach, F., et al., Predicting the particulate matter emissions from spray-guided gasoline direct-injection spark ignition engines. Proceedings of the Institution of Mechanical Engineers, Part D: Journal of Automobile Engineering, 2017. 231(6): p. 717-730, https://doi.org/10.1177/0954407016657453.

20. Mohd Murad, S., Camm, J., Davy, M., Stone, R. et al., Spray Behaviour and Particulate Matter Emissions with M15 Methanol/Gasoline Blends in a GDI Engine, SAE Technical Paper 2016-01-0991, 2016, https://doi.org/10.4271/2016-01-0991.

21. Fridriksson, H., Tuner, M., Andersson, O., Sunden, B. et al., Effect of Piston Bowl Shape and Swirl Ratio on Engine Heat Transfer in a Light-Duty Diesel Engine, SAE Technical Paper 2014-01-1141, 2014, https://doi.org/10.4271/2014-01-1141.

22. British Standards, BS EN 590 Diesel, Requirements and Test Methods. 2009.

23. Henry, M.P., Method and system for tracking sinusoidal wave parameters from a received signal that includes noise. GB Patent Application GB1619086.0, 11 November 2016.

24. Henry, M., O. Bushuev, and O. Ibryaeva, Prism Signal Processing for Sensor Condition Monitoring, in IEEE International Symposium on Industrial Electronics. 2017: Edinburgh, UK, https://doi.org/10.1109/ISIE.2017.8001451.

25. Henry, M., et al., The Prism: Efficient Signal Processing for the Internet of Things. IEEE Industrial Electronics Magazine, 2017. 11(4): p. 22-32, https://doi.org/10.1109/MIE.2017.2760108.

26. Leach, F., et al., Fast Coriolis Mass Flow Metering for Monitoring Diesel Fuel Injection. Flow Measurement and Instrumentation, 2017. 58: p. 1-5, https://doi.org/10.1016/j.flowmeasinst.2017.09.009. 


\section{Contact Information}

Felix Leach,

Dept of Engineering Science

University of Oxford

Parks Rd

Oxford

OX1 3PJ

UK

felix.leach@eng.ox.ac.uk

\section{Acknowledgments}

The authors would like to thank the Advanced Propulsion Centre Limited (grant number: PGC015) for funding this work. The authors would also like to acknowledge BP International for supplying the diesel fuel and Rheonik GmbH for support.
DIDS

DRS

ECN

ET

FIR

fps

LED

$m$

SOI bar gauge pressure

Brake specific fuel consumption

Coriolis Flow Meter

Direct Injector Driver System

Digital Rate Shaping

Engine Combustion Network

Energising time

Finite Impulse Response

Frames per second

Light-Emitting Diode

Some characteristic frequency

Start of injection

\section{Definitions/Abbreviations}

AFR

Air Fuel Ratio 